\title{
Nutrition, Minerals
}

National Cancer Institute

\section{Source}

National Cancer Institute. Nutrition, Minerals. NCI Thesaurus. Code C15926.

Role of minerals in cancer causation or prevention and in general health. 